\title{
Study on the Construction of Rural Regional Lifelong Education System by Using Modern Distance Education
}

\author{
Yingying Sun \\ School of Information Technology and Communication, Beihua University, Jilin, 132013 \\ wsyy_9@126.com
}

Keywords: Modern distance education; Countryside; Regional; Lifelong education

\begin{abstract}
With the development of new rural construction, the lifelong education of farmers in rural areas has attracted the attention of various parties. The construction of rural regional lifelong education system by using modern distance education has become an important means to balance educational resources and improve the quality of farmers, and is also a breakthrough in the realization of universal education and lifelong education of our people. Based on the correct orientation of the construction of rural regional lifelong education system, this paper analyzes and constructs a distance education model which is suitable for rural areas, determines the starting point of its educational means, and discusses the significance of the construction of the rural regional lifelong education system by using modern distance education.
\end{abstract}

\section{Introduction}

In the eighteenth National Congress of the Communist Party of China, some aims were put forward that in the "13th Five-Year" period, the agricultural modernization should be promoted, the construction of new socialist countryside should be accelerated, the urban and rural development should be balanced, the development of modern agriculture should be accelerated, the rural infrastructure construction and public services should be strengthened, the channels for farmers to increase income should be broadened, and the rural development system should be improved to build a beautiful home for farmer's happy life. The key to achieve these aims is to establish an effective rural lifelong education system, so as to improve the overall quality of farmers in rural areas. As a new educational technology means, modern distance education is suitable for the establishment of rural regional lifelong education system, and it is also an important means to build a learning society.

\section{Scientific Outlook on Development is Taken as the Guidance, and the Construction of Rural Regional Lifelong Education System is Orientated Correctly}

Since the reform and opening to the outside world, the construction of new countryside has always been a key issue in the process of socialist construction in China. However, from the actual implementation process, we found that the attention of government or functional departments at all levels to the new rural construction mostly reflected in the economic field, such as capital investment, preferential policies, administrative subsidies, etc. These are very important to the development of the countryside, but they all ignore the important forces of the rural traditional culture education and cultural heritage. The cultural education system in rural areas is not perfect, and the proportion of rural workers receiving re-education is insufficient, which lead to the lack of a scientific and cultural foundation for the construction of new countryside. At present, the core of the "three rural issues", which are highly concerned by the society, is the farmers' problem, and the root of the farmers' problem is the education of farmers. Therefore, the scientific outlook on development should be taken as the guidance, the construction of rural regional lifelong education system should be paid more attention to enable rural workers to be included in the universal lifelong education system, and the improvement of the scientific and cultural quality of rural workers and the construction of the new socialist countryside and modern new high-quality farmers should be taken as the starting point and foothold. The establishment and improvement of rural regional 
lifelong education system is the basic component of the overall development of adult education in China, is the key to realize the lifelong education for all, and also is the objective need and inevitable trend of rural educational reform and development.

\section{Reform and Innovation should be Insisted on, and the New Model of Modern and Effective Rural Distance Education should be Explored Actively}

In most rural areas of our country, the government management level is the three-level management system, namely, the county level, township level and village level. Therefore, in the construction of the network system of rural distance education, the combination of teaching and management should be considered fully, and the government management and local vocational education institutions should be taken as the support to establish the three level distance education system which takes the vocational education center in county area as the core, takes the rural vocational schools as the foundation, and takes the rural grassroots as the practice point.

The First Point is to Establish the Leading Position of Distance Education in County Vocational Education Center. At present, the county vocational education centers in the rural areas of our country already have a strong distance education strength in the teaching staff, experimental training bases and other aspects. Therefore, we should give full play to the leading role of distance education in vocational education centers in various counties to develop rural lifelong education, and promote the overall progress of rural education. Among them, we should be aware of that the educational resources and dissemination of vocational education centers should cover the information of the import of agricultural practical technology, new agricultural varieties and new technologies, and also should pay attention to the timeliness and interactivity of the delivery of policies and agricultural related information. In the process of training farmers, we should strengthen the guidance and training of specific agricultural technology, and also should pay attention to the quality education for farmers, in order to make them master the skills of learning modern agricultural knowledge autonomously. Also the modern distance education system should be used, and the education demonstration function of the vocational education system in county area facing to farmers, agriculture and countryside should be played. In the "radiation area", farmers should be guided to carry out the promotion of new agricultural varieties and new technologies, so as to play the role of demonstration and radiation.

The Second Point is to Strengthen the Infrastructure Construction of Distance Education in Township Vocational Schools. The township vocational schools are closely related to the farmers' actual production and life, and understand the local conditions and the actual needs of farmers, so the construction of the infrastructure network of local regional distance education based on township vocational schools is easy to form a teaching area, and it is also easy to deploy, arrange and implement the recent development goals of one countryside in the region. Government departments should increase the basic investment of distance education in township vocational schools, strengthen the construction of teaching staff in township vocational schools, and actively communicate with other local agricultural colleges and universities to introduce a batch of college students and specialized personnel who have relevant subject knowledge and would like to serve the rural base voluntarily to engage in education and teaching work. The distance education system of the township vocational school should be taken as the basis to exchange the information with outside world. In this way, farmers living in rural areas can not only receive scientific and technology guidance, but also understand the supply and demand information of agricultural products outside the region, and rationally plan the varieties or quantities of planting or breeding, so as to avoid the economic losses caused by the over planting or farming in the whole country.

The Third Point is to Play the Guiding Role of the Village Level Distance Education Site. Village is the lowest administrative unit in rural areas, so the village level site is the bottom node in the lifelong education system of farmers. In actual work, the village level education website should fully and rationally play its role in the unified organization of rural township vocational school. In the village, the villagers who have a certain cultural knowledge and aspire to serve the rural education and culture should be chosen as the part-time teachers, so that they can obtain 
information through distance education network and then deliver it to the local villagers timely, and the specific farmer education activities can be extended in the form of radiated pattern in the receiving terminal of the distance education network.

\section{Farmers' Scientific and Technological Guidance and Training Should be Taken as the Breakthrough Point to Promote the Development of Rural Lifelong Education}

To some extent, the success or failure of the development of modern and efficient agriculture depends crucially on the skills that farmers possess. Therefore, in order to make the construction of new socialist countryside achieve real results, promote and develop modern rural industry, and change the current situation that farmers have low education level, cultivating and bringing up a large number of new type of farmers who have culture and knowledge and can manage is the root. Only by changing the current situations of the low quality of farmers, backward technology and no road to wealth, can we bring new ideas to the development of agricultural industry, and lay a solid and steady human resources foundation for the construction of new countryside. In the rural areas, the construction of lifelong education system and the cultivation of the new type of farmers by using modern distance education means must take the training of science and technology as the starting point.

Modern distance agriculture education system is convenient, flexible and effective, and has gradually become the cradle of rural cadres education and training, and the science and technology training base of basic agricultural science and technology personnel, rural science and technology demonstration households and main farmers. Through radio, television, computer network, books, audio-visual products and other information carriers, the rural distance network education system delivers a large number of practical agricultural technologies and agricultural information to farmers in an effective and quick means. In the rural regional lifelong education system based on modern distance education, modern media technology should be used to reorganize the basic, systematic and universal post training of farmers and academic education courses to form the systematic curriculum system. Modern distance education means with large capacity, wide coverage and fast information transmission should be taken as the technical support to realize the leapfrog development of farmers' science and technology education training in rural areas.

The modern distance education method is used to integrate the training resources, establish a comprehensive coordination organization, perfect the cooperative mechanism of agricultural science and education, strengthen the cooperation with teaching, research, economy and other departments, gradually form the combination of rural areas and the forces of education, science and technology, and form the pattern of cooperation between rural areas and market economy. The resources integration and complementary advantages should be carried out, the modern media means, such as television, telephone, computer network, should be used fully, the network of "agricultural technology radio wave into the home" should be constructed, and the farmers should be leaded to renew their learning ideas. Farmers should be taught the science and technology which they can understand, use and get rich, so that the farmers can learn to acquire the knowledge they need by means of distance education network tools, and gradually change the learning pattern from passive acceptance to active acquisition, and form the habit of active learning, so as to gradually form the lifelong education system in rural areas.

\section{The Modern Rural Regional Lifelong Learning System Should be Constructed to Promote the Construction of a Learning Society}

The construction of rural regional lifelong education system by using modern distance education is a systematic project, and also it is the key content to promote the construction of learning society in our country. China is a large agricultural country, and the proportion of farmer groups accounts for $70 \%$ of the total population of the country. The improvement of the quality of farmer groups plays a key role in the improvement of the overall quality of our people. The lifelong education in rural areas bears the important responsibility of transforming a large number of rural population 
resources of our country into new human resources, improving the overall quality of the people and promoting the harmonious and balanced development of the social economy. The distance education network has solved many difficulties in rural regional education system, such as the wide distribution of education areas, the scattered education objects, the limited practical education faculty, the lack of education and teaching facilities, and so on. Through distance education network system and starting from the actual situation of the country, the modern means of network communication should be used fully to carry out the education and training activities, so as to gradually form the information network education system which covers the vast rural areas. It not only helps to overcome the limitations of high dependence on the region and teaching resources in the process of adult education in the traditional sense, but also helps the broad masses of farmers share the education and information resources in the network through the remote information network, so that they can improve their quality in a broader space and time. Through reforming the traditional way of rural adult education, the modern education technology is applied to the field of adult education in rural areas, and the overall modernization level of rural adult education is driven by the informatization of rural adult education, so as to greatly enhance the quality and efficiency of rural adult education and teaching. With the introduction and promotion of lifelong learning concepts nationwide, the rise of rural surplus labor education and training, and the rapid development of community education in China, the construction and development of rural regional lifelong education system by using modern distance education has become a new subject. The construction of the lifelong education system in rural areas will become the practical action of our country to realize the concept of "universal education", "equality of educational opportunity" and "lifelong learning". The construction and development of rural regional lifelong education system nationwide based on modern distance education system will promote the continuous development of rural economy in China, the continuous advancing of society sustainability, the continuous improvement of the quality of rural population and the harmonious development of the whole society.

\section{Acknowledgements}

This paper is one of the research achievements of education and teaching research topic

"Optimization and Research of "Educational Technology Foundation" Course Teaching Resources for Normal Students” of Beihua University in 2014.

\section{References}

[1] Y.Y.Sun, C.S.Zhang and F.Lv: Research on the Ability Cultivation of the Digital Media Technology of Normal College Students[J], China Educational Technology and Equipment, 2014(24).(In Chinese)

[2] Y.Y.Sun: Exploration and Practice of Educational Informatization[J], Education and Vacation, 2012(11).(In Chinese) 